\title{
Biosynthesis of Copper and Iron Nanoparticles using Neem (Azadirachta indica) Leaf Extract and their Anti-bacterial Activity
}

\section{${ }^{1}$ *YILLENG, TM; ${ }^{1}$ SAMUEL, NY; ${ }^{1}$ STEPHEN, D; ${ }^{2}$ AKANDE, JA; ${ }^{3}$ AGENDEH, ZM; ${ }^{4}$ MADAKI, LA}

\author{
${ }^{1}$ Department of Chemistry, Kaduna State University, Nigeria \\ ${ }^{2}$ Department of Chemistry, Ahmadu Bello University, Zaria, Nigeria \\ ${ }^{3}$ Department of Chemical Sciences, Bingham University, Karu, Nigeria \\ ${ }^{4}$ Department of Chemistry, Gombe State University, Gombe, Nigeria \\ *Corresponding Author Email: yilleng.moses@kasu.edu.ng
}

\begin{abstract}
Neem leaves extract was use to synthesize metal (iron and copper) nanoparticles. The nanoparticles were characterized using Scanning Electron Microscope (SEM), Fourier Transform Infrared (FTIR) and UV-Vis spectrometer. The formation and stability of the reduced metal nanoparticles in the colloidal solution were monitored by UV-Vis spectrophotometer analysis. Their peaks of CuNPs and FeNPs were determined with a particles size in the range of $250 \mathrm{~nm}-550 \mathrm{~nm}$ and $250 \mathrm{~nm}-350 \mathrm{~nm}$ and have shapes of spherical and dendrimer respectively. The zone of inhibition by CuNP on gram negative bacteria (Staphylococcus Aureus) is $20 \mathrm{~mm} \pm 1$ while on gram positive bacteria (Escherichia Coli) is $12.5 \mathrm{~mm} \pm 1$. Thus, the synthesized metal nanoparticles prove to have very high anti-bacterial activity on both Staphylococci aureus and Escherichia coli. Copper nanoparticles exhibits high antibacterial activity compared to iron nanoparticles.
\end{abstract}

DOI: https://dx.doi.org/10.4314/jasem.v24i11.20

Copyright: Copyright $\left({ }^{\circ} 2020\right.$ Yilleng et al. This is an open access article distributed under the Creative Commons Attribution License (CCL), which permits unrestricted use, distribution, and reproduction in any medium, provided the original work is properly cited.

Dates: Received: 10 October 2020; Revised: 11 November 2020; Accepted: 20 November 2020

Keywords: Copper, Iron, nanoparticles, Anti-bacterial activity

Nanoparticles can be synthesized by physical method which is through evaporation, laser ablation, vaporization; while chemical method which is the second method is one which the metal ions in solution is reduced in conditions favoring the subsequent formation of small metal clusters or aggregates. This chemical method is group into classical method and radiation chemicals. But biosynthesis is a form of chemical method that chemicals that are not harmful and naturally occurring reducing agent such as plant extract or biological microorganisms such as fungi, bacteria are used It was also reported that the metal nanoparticles formation is as the result of the antioxidant and reducing property of the phytochemicals, (Subhankari and Nayak, 2013). Copper is a widely used material in the world because of various applications in electricity, optics, biomedical and catalysis. Copper nanoparticles is referred to as effective bactericidal metal because it is toxic to microorganism and non-toxic to animal cell; and therefore, consider to be save for human being in the aspect of food packaging and water treatment (Saranyaadevi et al., 2014). Due to the stability of copper nanoparticles supported on a matrix and their disinfecting properties, copper nanoparticles can be used as a bactericide agent to coat hospital equipment (Subhankari and Nayak, 2013). Iron nanoparticles are given less attention due to it extreme reactivity which has rather made it difficult to study. However, iron has very potent magnetic and catalytic property (Shah et al., 2014).

The plant that is studied in this work is Azadirchta indica (Neem); it is a tree in mahogany family. It is used in controlling blood sugar level and also clean blood. Products from Neem are believed to be anthelmintic, antifungal, antidiabetic, antibacterial, antiviral, Neem Plant Leaves extract is used to produce Iron contraceptive and sedative Various plant part can be used in the synthesis of metal nanoparticles i.e. the leaf, stem, root, flower and seeds (Saranyaadevi et al., 2014). In this article, a simple one step method for the synthesis of metal nanoparticles by the reduction of aqueous copper and iron ions using leaf extracts of Azadirachta indica at room temperature without using any additive protecting the metal nanoparticles from aggregation. In this work the potential of copper and iron nanoparticles was investigated, and the application of plant-based copper and iron 
nanoparticles in the development of antibacterial nanoparticles was carried out by agar disc diffusion method against Escherichia coli, and Staphylococcus aureus. The production of the copper and iron nanoparticles through bio-reduction of copper and iron ions by the Azadirachta indica leaf extract and their antibacterial test in this work may provide valuable technical parameters for industrialization of the biosynthetic technique and further antibacterial application of the nanoparticles. The objective of this paper is therefore to biosynthesize nanoparticles of copper and iron using Neem (Azadirachta indica) leaf extract and evaluate their anti-bacterial activity.

\section{MATERIALS AND METHODS}

Materials: Azadirachta indica (Neem) leaf was collected directly in Kaduna North, Kaduna, Nigeria. The precursors $\left(\mathrm{Cu}\left(\mathrm{NO}_{3}\right)_{2} .3 \mathrm{H}_{2} \mathrm{O}\right.$ and $\left.\mathrm{FeCl}_{3} .6 \mathrm{H}_{2} \mathrm{O}\right)$ were obtained from Sigma Aldrich.

Preparation of extract: The extract was prepared by modifying the method reported by Saranyaadevi et al., (2014). The neem leaves collected were washed several times with water and rinsed with deionized water for the removal of impurities. $30 \mathrm{~g}$ of sliced neem leaf was then boiled in $100 \mathrm{~cm}^{3}$ of deionized water for $10 \mathrm{~min}$ and was filtered using Whatman's no. 1 filter paper. The filtrate was collected in clean, dry conical flask and kept for further use.

Preparation for Copper Nanoparticles (CuNPs): In copper nanoparticles synthesis, the crude plant extract is mixed with the aqueous solution of $\mathrm{Cu}\left(\mathrm{NO}_{3}\right)_{2} .3 \mathrm{H}_{2} \mathrm{O}$ in $1: 4$ proportion. $25 \mathrm{~cm}^{3}$ of prepared crude Neem leaf extract is mixed with $100 \mathrm{~cm}^{3}$ of $0.001 \mathrm{M} \mathrm{Cu}\left(\mathrm{NO}_{3}\right)_{2}$. $3 \mathrm{H}_{2} \mathrm{O}$ solution and solution was then allowed for a day in dark place. The change in colour of the mixture from brown to sea green within few minutes indicates the formation of metal nanoparticles. On allowing the solution for a day, it becomes darker solution than previous colour (Saranyaadevi et al., 2014).

Preparation of Iron Nanoparticles (FeNPS): In FeNPs synthesis, the ratio of mixture of plant crude extract to $0.001 \mathrm{M} \mathrm{FeCl}_{3} .6 \mathrm{H}_{2} \mathrm{O}$ (precursor) is $1: 1.40 \mathrm{~cm}^{3}$ of plant extract is mixed with $40 \mathrm{~cm}^{3}$ of $0.001 \mathrm{M}$ hydrated ferric chloride solution at the temperature range of $50-60^{\circ} \mathrm{C}$. The change in colour from brown to black indicates the formation of iron nanoparticles (Saranyaadevi et al., 2014).

Characterization of CuNPs and FeNPs: The synthesize metal nanoparticles were centrifuge at $400 \mathrm{rpm}$ for $15 \mathrm{~min}$, and the supernatant was then again centrifuge for $30 \mathrm{~min}$ at $14,000 \mathrm{rpm}$. The sediment was then collected with $0.5 \mathrm{~cm}^{3}$ deionized water and kept for SEM (model is JSM-6480-LV made by Phenom World Country of manufacture, Eindhoven the Netherlands) and FTIR analysis. The morphology of CuNPs and FeNPs was taken using SEM and the functional group responsible for reduction of metals to metal nanoparticles was recorded using FTRI. The UV-Vis spectroscopy measurement was recorded at the wavelength of $200 \mathrm{~nm}, 250 \mathrm{~nm}, 300 \mathrm{~nm}, 350 \mathrm{~nm}$, $400 \mathrm{~nm}, 450 \mathrm{~nm}, 500 \mathrm{~nm}, 600 \mathrm{~nm}, 650 \mathrm{~nm}, 700 \mathrm{~nm}$ and $750 \mathrm{~nm}$ a modified procedure as reported by Saranyaadevi et al., (2014) The ratio of dilution of metal nanoparticles to deionized water is $1: 10$, which is transferred into the cuvette for analysis in which the absorbance at the above wavelengths were recorded. The UV-Vis Spectroscopy used is Jenway; 6405 UV/Vis. Spectrophotometer.

Antibacterial of copper and iron nanoparticles: The antibacterial activity of the metal nanoparticles was observed using well diffusion method (Krishnamoorthy and Jayalakshmi, 2012). The pathogen (bacteria) used are Staphylococcus aureaus and Escharichia coli. The media use is Mueller Hinton Ager. Sterilized media was transferred into a well sterilized environment. $20 \mathrm{~cm}^{3}$ of Mueller Hinton agar was transferred into clean, dried and sterilized Petri dishes; then allowed to cool so as to solidify. On solidification, the culture bacteria were rubbed or spread on the surface of the solidified Mueller Hinton agar in the Petri dishes. Using a sterile hole borer, hole (cup) was then made or produced in the media (Mueller Hinton agar and the bacteria in it) and the cup (hole) is then filled with $0.1 \mathrm{~cm}^{3}$ of the synthesized nanoparticles. The plates (Petri-dishes) were then incubated in an upright position for $24 \mathrm{hrs}$ at $37^{\circ} \mathrm{C}$. After incubation, the diameter and growth inhibition zones are recorded and the mean value is then recorded. The same procedure is done for each metal nanoparticle.

\section{RESULTS AND DISCUSSION}

UV-Vis Spectroscopy analysis: The results obtained in Figure 1 illustrates the formation and stability of FeNPs and CuNPs from their respective salts which gives characteristic peaks at $24 \mathrm{hrs}$ time interval at different wavelength using UV-visible spectroscopy. UV-visible spectroscopy analysis was done in the range of 200-800 $\mathrm{nm}$ and the maximum absorbance was observed at around 250 and $350 \mathrm{~nm}$ regions for the formation of iron nanoparticles due to the excitation of surface plasmon vibrations and the absorption peak at $250 \mathrm{~nm}$ and $350 \mathrm{~nm}$ is 2.886 and 1.91 respectively. For that of copper nanoparticles, two peaks (resonance) were observed, strong peak at $250 \mathrm{~nm}$ with absorbance of 2.718 which is attributed to the formation of copper nanoparticles and a weak 
broad peak or band at $550 \mathrm{~nm}$ with absorbance of 0.079 which may be attributed to the formation of cupric oxide nanoparticles (CuO) (Abboud et al., 2014). This result of CuNPs is in accordance with a previous research which shows that the peak is at the region of 560-640nm.

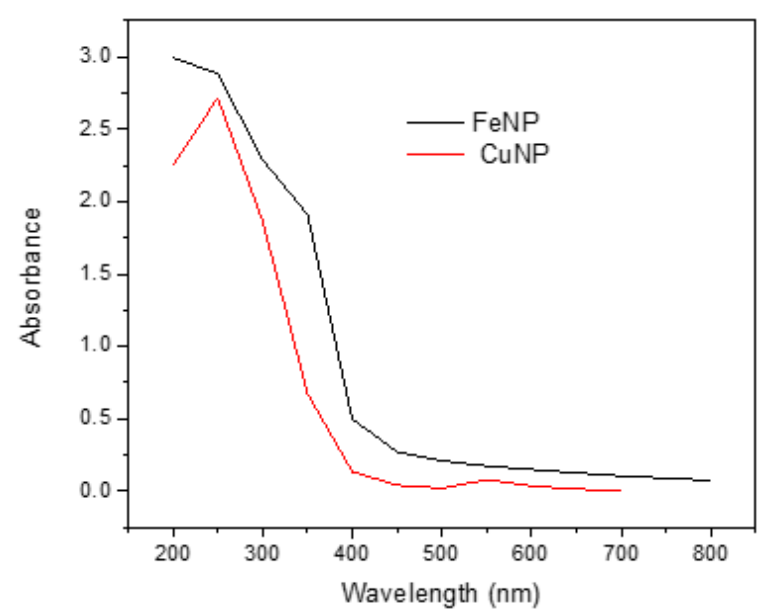

Fig 1. UV-Vis Spectrophotometry results of FeNP and CuNP.
FTIR Analysis: The FTIR result obtained from synthesized iron and cupper nanoparticle is shown in figures 2 and 3. The FT-IR analysis was used to determine the molecules and/or functional group that are probably present in the synthesized copper Nanoparticles. Figure 2; represents the spectra of FeNP with peaks at $3268.9 \mathrm{~cm}^{-1}$ and $1636.3 \mathrm{~cm}^{-1}$. The strong broad absorption peak at $3268.9 \mathrm{~cm}^{-1}$ is assigned to $\mathrm{O}-\mathrm{H}$ stretching of carboxylic acid; and the peak at $1636.3 \mathrm{~cm}^{-1}$ is assigned to $\mathrm{C}=\mathrm{O}$ stretching in amides arisen due to the carbonyl stretching protein (Naik et al., 2014) or N-H bend from amides (primary amide). Figure 4.3; represent the spectra of CuNP with various peaks at $3291.2 \mathrm{~cm}^{-1}, 1636.3 \mathrm{~cm}^{-1}$ and $1017.6 \mathrm{~cm}^{-1}$. The strong broad absorption peak at $3291.2 \mathrm{~cm}^{-1}$ is assigned to $\mathrm{O}-\mathrm{H}$ stretching of carboxylic acid like gallic acid, acetic acid and gibberellic acids; the peak at $1636.3 \mathrm{~cm}^{-}$ ${ }^{1}$ is assigned to $\mathrm{C}=\mathrm{O}$ stretching in amides (tertiary amides) or $\mathrm{N}-\mathrm{H}$ bend from amides (primary amide) probably like amino acids or protein and the peak at $1017.6 \mathrm{~cm}^{-1}$ indicates the C-F stretching from alkyl halide. The possible secondary metabolites include tannins, saponins, terpinoid and terpenes etc.

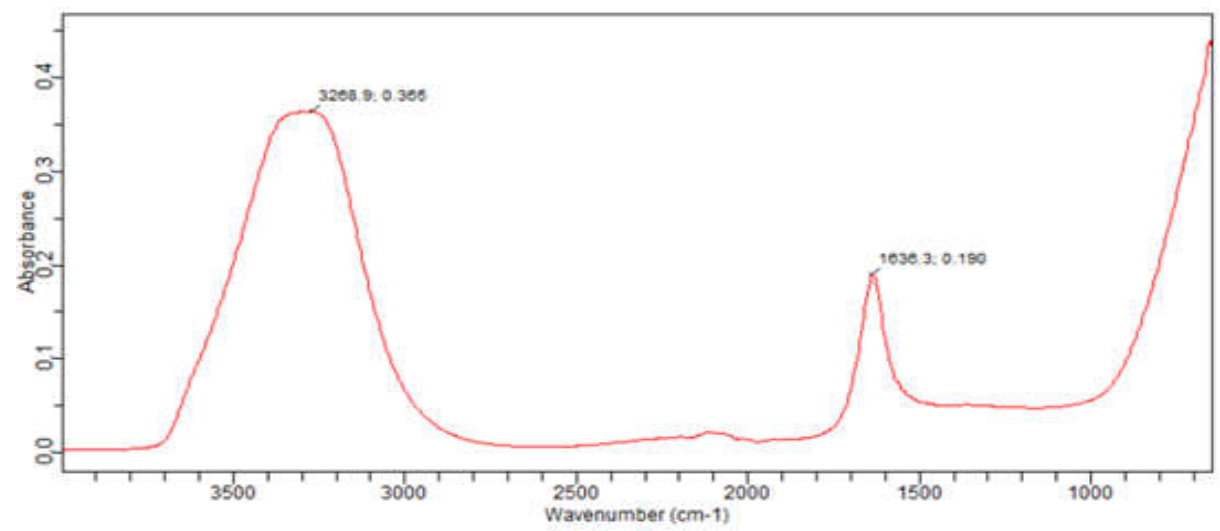

Fig 2 The FTIR analysis of FeNPs

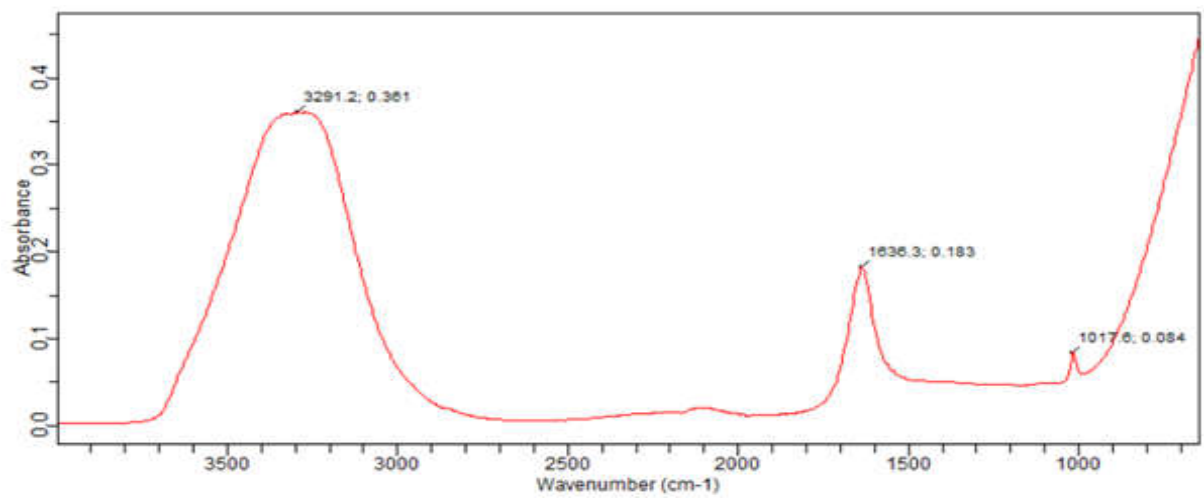

Fig 3 The FTIR analysis of CuNPs

SEM analysis: The result obtained using SEM analysis is shown above in the figure 4 and 5. This SEM was carried out to get the morphology of the synthesized nanoparticles. Figure 4, shows the iron nanoparticles synthesized from neem leaf extract, which is having a dendrimer kind of structure; it is highly branched with 
a central core. Figure 5 represents the $\mathrm{Cu}$ nanoparticles synthesized using hydrated copper nitrate as the precursor. The shape in which the CuNP is having is spherical in shape (Heera et al., 2015) The electrostatic interactions and hydrogen bond between the bio-organic capping molecules bond are responsible for the synthesis of copper nanoparticles using plant extract (Saranyaadevi et al., 2014).

Antibacterial analysis: The antibacterial study of biosynthesized CuNPs and FeNPs were established against both the gram negative and gram-positive pathogenic bacteria such as Staphylococcus aureus (gram positive), E-coli (gram negative) using well diffusion method. However, the zone of inhibition (ZOI) was observed to be more in gram negative bacteria when compared to gram positive bacteria. This is mainly due to the differences in bacterial pathogen's membrane structures. The zone of inhibition by FeNP on the gram negative (Staphylococcus Aureus) is $15 \mathrm{~mm} \pm 1$ while on gram positive bacteria (Escherichia Coli) is $9 \mathrm{~mm} \pm 1$. The zone of inhibition by CuNP on gram negative bacteria (Staphylococcus Aureus) is $20 \mathrm{~mm} \pm 1$ while on gram positive bacteria (Escherichia Coli) is $12.5 \mathrm{~mm} \pm 1$. From the result obtained, it shows that the CuNPs has higher antibacterial activity compared to the FeNPs.
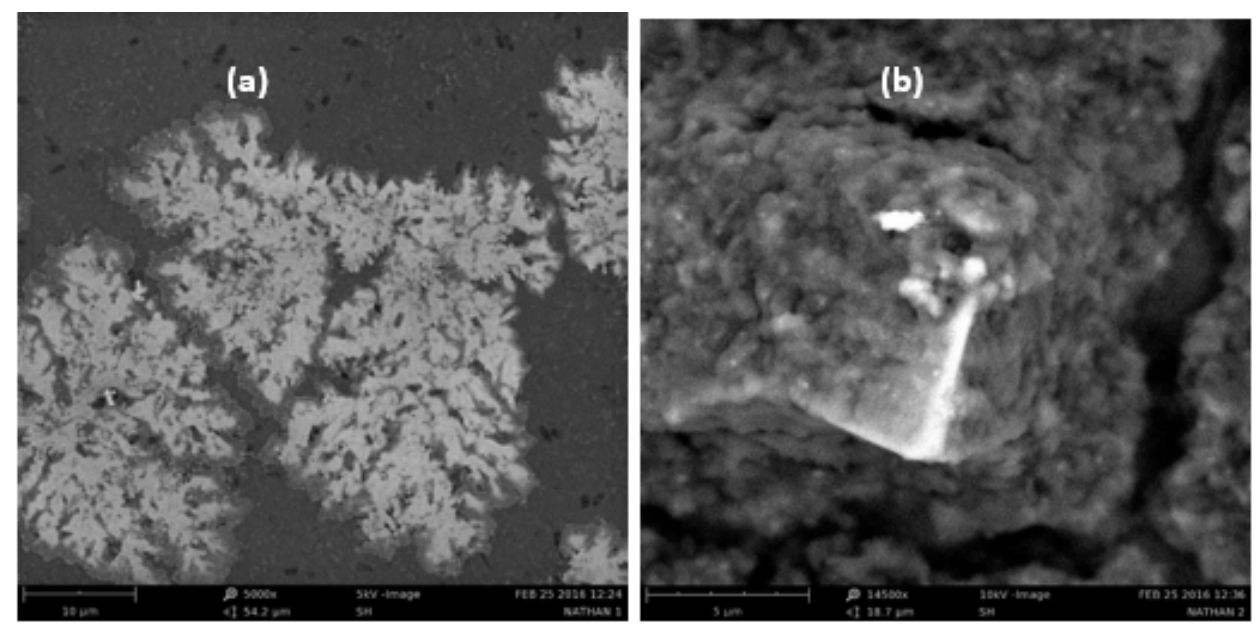

Fig 4a SEM of FeNPs and $b$ is SEM of CuNP

\begin{tabular}{llll}
\multicolumn{4}{c}{ Table 1: Zone of Inhibition of CuNP and FeNP against bacteria species } \\
\hline $\mathrm{S} / \mathrm{N}$ & Species & FeNP & CuNP \\
\hline 1 & E. Coli & $9 \mathrm{~mm} \pm 1$ & $12.5 \mathrm{~mm} \pm 1$ \\
2 & Staphylococci aureus & $15 \mathrm{~mm} \pm 1$ & $20 \mathrm{~mm} \pm 1$ \\
\hline
\end{tabular}

Conclusion: The CuNPs and FeNPs were successfully synthesized by using the extracts obtained from Azadirechta indica plant leaves for the anti-bacterial study, which provides cost effective and eco-friendly way for synthesis of both nanoparticles. The functional group present in the leaf extract was confirmed by FTIR analysis. The synthesized nanoparticles were further analyzed using UVspectrophotometer, SEM and TEM. The maximum Zone of Inhibition was found to be more in gram negative bacteria compared to gram positive bacteria. Based on this investigation CuNPs has higher antibacterial activity compared to the FeNPs.

\section{REFERENCES}

Abboud, Y; Saffaj, T; Chagraoui, A; Bouari, AE; Brouzi, K; Tanane, O; and Ihssane, B (2014). Biosynthesis, Characterization and Antimicrobial Activity of Copper Oxide Nanoparticles (CONPs)
Produced Using Brown Alga Extract (Bifurcaria Bifurcata). Appl. Nanoscience. 4 (5):571-76.

El-Nour, KMMA; Eftaiha, A; Al-Warthan, A; Ammar, RAA (2010). Synthesis and Applications of Silver Nanoparticles. Arabian J. Chem. 3(3). 135-140

González, F; María, LB; Antonio, B; Laura, C; Jesús, AM (2015). Biosynthesis of Silver and Platinum Nanoparticles Using Orange Peel Extract: Characterisation and Applications. IET Nanobiotechnology. 9 (5): 252-58.

Gopinath, M; Subbaiya, R; Masilamani, S; Suresh, D (2014). Synthesis of Copper Nanoparticles from Nerium Oleander Leaf Aqueous Extract and Its Antibacterial Activity. Int J Curr Microbiol App Sci. 3 (9): 814-18. 
Heera, P; Shanmugam, S; Ramachandran, J (2015). Green Synthesis of Copper Nanoparticle Using Gymnema Sylvestre by Different Solvent Extract. Int J Curr Res Acad Rev. 3 (10): 268-75.

Krishnamoorthy, P; Jayalakshmi, T (2012). Preparation, characterization and synthesis of silver nanoparticles by using phyllanthus niruri for the antimicrobial activity and cytotoxic effects. J. chem. Pharma. Res. 4(11): 4783-4794

Kuppusamy, P; Yusoff, MM; Maniam GP (2016). Biosynthesis of Metallic Nanoparticles Using Plant Derivatives and Their New Avenues in Pharmacological Applications-An Updated Report. Saudi Pharmaceutical J. 24 (4): 473-484

Marchiol, Luca (2012). Synthesis of Metal Nanoparticles in Living Plants. Italian $J$. Agronomy. 7 (3): 37.

Mehmood, A; Ghulam, M; Tariq, MB; and Rehana, K (2017). Phyto-Mediated Synthesis of Silver Nanoparticles from Melia Azedarach L. Leaf Extract: Characterization and Antibacterial Activity. Arabian J. Chem. 10: S3048--S3053.

Naik, BR; Swarna, G; Yuvo, S; Satyavathi, R; Daravath, SS; Ramachandra, PR (2014). BioSynthesis of Silver Nanoparticles from Leaf Extract of Pongamia Pinnata as an Effective Larvicide on Dengue Vector Aedes Albopictus (Skuse) (Diptera: Culicidae). Adv. Entomology, Sci. Res. Pub. 2 (02): 93.

Pattanayak, M; Debabrata, M; Nayak, PL (2013). Green Synthesis and Characterization of Zero Valent Iron Nanoparticles from the Leaf Extract of Coffea Arabica (Coffee). American-Eurasian J Sci. Res. 8 (4): 184-87.
Sadowski, Z (2010). Biosynthesis and Application of Silver and Gold Nanoparticles. In Silver Nanoparticles. InTech. 13(1): 257-276

Saranyaadevi, KV; Subha, RS; Ernest, R; Renganathan, S (2014). Synthesis and Characterization of Copper Nanoparticle Using Capparis Zeylanica Leaf Extract. Int J Chem Tech Res. 6 (10): 4533-41.

Shah, S; Sumita, D; Mousumi, C; Raji, V; Murtaza, H (2014). Green Synthesis of Iron Nanoparticles Using Plant Extracts. Int J Biol Pharm Res. 5(7): 549-52.

Shobha, G; Moses, V; Ananda, S (2014). Biological Synthesis of Copper Nanoparticles and Its Impact. Int. J. Pharm. Sci. inv. 3 (8): 28-38

Subhankari, I; Nayak, PL (2013). Synthesis of Copper Nanoparticles Using Syzygium Aromaticum (Cloves) Aqueous Extract by Using Green Chemistry. World J Nano Sci Tech. 2 (1): 14-17.

Verma, A; Mohan SM (2016). Controllable Synthesis of Silver Nanoparticles Using Neem Leaves and Their Antimicrobial Activity. J. of Radiation Res. and Applied Sci. 9 (1): 109-15.

Yasmin, A; Kumaraswamy, R; Shanmugam R (2014). Optimization and Stabilization of Gold Nanoparticles by Using Herbal Plant Extract with Microwave Heating. Nano Convergence. 1 (1): 12. 